\title{
Fertility desire and associated factors among people living with HIV attending antiretroviral therapy clinic in Ethiopia
}

\author{
Dereje Bayissa Demissie ${ }^{1 *}$, Bosena Tebeje ${ }^{2}$ and Temamen Tesfaye ${ }^{2}$
}

\begin{abstract}
Background: The reproductive decisions made by PLHIV and their partners have a long-term consequences for the survival and wellbeing of their families and a society at large. Evidence relating to fertility and reproductive intentions among PLHIV is rare, despite the fact that more than $80 \%$ of PLHIV are of reproductive age. The aim of the study was to determine fertility desire and associated factors among PLHIV attending ART clinic in Fitche Hospital.

Methods: A facility based cross-sectional study design with both quantitative and qualitative data collection methods was employed from February21-April 20th, 2013. The study participants were selected by using simple random sampling technique. A pre- tested structured questionnaire was used to collect data. Both bivariate and multivariate logistic regressions were used to identify associated factors.

Result: The prevalence of fertility desire of PLHIV in Fitche Hospital was 133(39.1\%) with 95\% Cl of (34.3\% -44.3\%). This study identified that factors found to be associated with fertility desire were: - Age from 18-29y [AOR $=3.95$, 95\% Cl: $1.69-9.22)$ and 30-39y ( $\mathrm{AOR}=3.91,95 \% \mathrm{Cl}: 1.90-8.19)]$, marital length $\leq 4 \mathrm{y}[\mathrm{AOR}=5.49,95 \% \mathrm{Cl}: 2.08-14.51)$, within 5-9y ( $\mathrm{AOR}=4.80,95 \% \mathrm{Cl}: 2.14-10.78)$ and 10-14y ( $\mathrm{AOR}=2.82,95 \% \mathrm{Cl}: 1.19-6.63]$, had not biological living children $[A O R=11.42,95 \% \mathrm{Cl}: 3.27-39.90)$ and had more than one child (AOR $=3.67,95 \% \mathrm{Cl}: 1.27-10.62)]$, community pressure [AOR $=3.67,95 \% \mathrm{Cl}: 1.54-8.70]$, partner fertility [AOR $=7.18,95 \% \mathrm{Cl}: 3.39-15.22)]$, duration HIV diagnosis $\leq 1 \mathrm{y}$ $[\mathrm{AOR}=4.99,95 \% \mathrm{Cl}: 1.91-13.09]$, disclosed HIV serostatus [AOR $=3.9,95 \% \mathrm{Cl}: 1.37-11.10]$ and partner sero-difference $[A O R=2.05,95 \% \mathrm{Cl}: 1.01-4.15]$ were some of the factors significantly associated with fertility desire.

Conclusion: The prevalence of fertility desire of PLHIV in the study area was 39.1\%. In this study:- age, marital length, biological child, partner, community pressure, duration of HIV-diagnosis, discordant HIV-test and disclosure of HIVserostatus to partner were demonstrated to have more associations with fertility desire among PLHIV, therefore, these factors should be emphatically considered during PLHIV's reproductive health program development.
\end{abstract}

Keywords: People living with HIV, Ethiopia, Fertility desires

\section{Background}

Human immuno virus (HIV), is the virus that causes acquired immunodeficiency syndrome (AIDS), has become one of the world's most serious health and development challenges [1]. The first case was reported in 1981 and currently, more than 30 years later, there are approximately 34 million people living with HIV and nearly 30million people have died by AIDS-related causes since

\footnotetext{
* Correspondence: derebayu@gmail.com

${ }^{1}$ Department of Nursing and Midwifery, College of Medicine and Health Science, Ambo University, Ambo, Ethiopia

Full list of author information is available at the end of the article
}

the beginning of the epidemic [1,2]. Ethiopia is among the countries that are on top of a list of nations hard hit by HIV pandemic. According to Ethiopia Demographic Health Survey reported in 2011, the prevalence of HIV among reproductive age (15-49 years) were $1.5 \%$ and the prevalence of HIV among women were $1.9 \%$ whereas in men $1 \%$ [3].

Fertility desires is intention to have more children despite the diagnosis of HIV, whereas intentions denote a commitment to implementing fertility desires. Therefore, intention comprises both desire and planning aspects. Desire for a child means that expression of 
PLHIV to have child in the future, despite the diagnosis of HIV [4].

Historically, policies in many countries discouraged HIV-infected individuals from having children in order to reduce the number of children born with HIV or born to HIV-infected parents, but a more flexible approach towards reproductive choices of PLHIV has now emerged. This shift has been mainly informed by a reproductive rights approach and universal access to PMTCT/ART interventions and the availability of assisted reproductive techniques for HIV infected people in developed countries which have dramatically reduced the chances of sexual and perinatal HIV transmission $[5,6]$. This has given rise to the growing recognition of the rights of PLHIV to have children or prevent unintended pregnancies [7]. It is important to study fertility desires and associated factors among PLHIV because HIV can be transmitted in the same way that pregnancy is achieved, that is, through unprotected hetero-sexual intercourse [8].

Thus, unprotected sex among PLHIV, in order to conceive, carries the risk of transmitting HIV to sexual partners and subsequently to children during birth or breast feeding. The reproductive decisions made by PLHIV and their partners have long-term consequences for the survival and wellbeing of their families and society at large [9]. The desire and intent to have children among HIV infected individuals may increase because of improved quality of life and survival following commencement of anti-retroviral treatment and reproductive health service as well [5].

The complex relationship between fertility and HIV/ AIDs threatens the preventive strategies against the HIV epidemic in countries like Ethiopia, where the fertility rate is still high and PMTCT utilization low [10]. While the Government of Ethiopia's HIV policy is supportive of HIV and reproductive health services integration, these services remain predominantly vertical in terms of program administration, funding and service delivery [11]. Reproducing ("giving life") for HIV-positive individuals means transcending the death that appears near, and these figures may be much higher in low-resource settings, where the disease prognosis is still very poor [3]. PLHIV, just like the general population, desire to have children after learning of their HIV-status [12-14]. Unlike the general population, people who know they are HIV infected have additional issues to consider, including potential health risks for (re)infections, vertical transmission of HIV and orphaning. Despite these concerns, studies show that some PLHIV still wish to have children for a range of reasons [5,15]. Most couples living with HIV are of child bearing age and facing difficulty in their choice concerning sexuality and child bearing [13].

Most recently, fertility issues in PLHIV are becoming increasingly important [4]. In a setting with high HIV prevalence and high fertility rates, addressing fertility issues of PLHIV is crucial. However, understanding of the factors associated with fertility desires of PLHIV in Ethiopia is remarkably low. In 2009, only 8 percent of HIV-positive pregnant women received ARV prophylaxis [11]. Evidence relating to fertility and reproductive intentions among PLHIV is rare [16], despite the fact that more than $80 \%$ of PLHIV are of reproductive age [7]. HIV positive individuals may or may not have desire to have children and want to use family planning. Hence this study was conducted to identify fertility desires and associated factors among PLHIV attending ART clinics of Fitche Hospital.

\section{Methods}

\section{Study setting}

The study was conducted from February 21st to April 20th of 2013, in Fitche Hospital ART clinic which is found in Fitche town, North shoa Zone, Oromiya Regional State in Ethiopia and 115 Kilo meters North of Capital city of Addis Ababa. According to the national population and housing census of 2007/08 of Ethiopia, the projected population of the zone for 2013 was estimated to be $1,388,617$ and from those $6,951,87(50.06 \%)$ were males. The zone has 2 hospitals, 48 health centers and 268 functioning health posts with estimated potential health service coverage of $91.6 \%$. The total numbers Reproductive ages on HAART and Pre-ART in north shoa zone was 8821 .

Fitche Hospital provides different services like Outpatient department, Inpatient department, Maternal Neonatal Child Health and Pre-ART and ART services by different disciplines. The total numbers of reproductive age PLHIV in Fitche Hospital was 2131 (from those 1211 on ART and 920 Pre- ART respectively).

\section{Study design}

A facility based cross-sectional study design with both quantitative and qualitative data collection methods was conducted in ART clinic of Fitche Hospital. The study inclusion criteria were having attended for at least three months, availability of HIV sero-status results, HIV positive diagnosis and reproductive age, 18 to 49 years of age for women and 18 years and above for men.

\section{Sampling procedure and sample size determination}

For the quantitative study sample size was determined by using single population proportion formula by considering 50\% proportion of fertility desire among PLHIV with 95\% confidence interval and 5\% marginal error. Since the total numbers of patients enrolled to ART clinic at Fitche Hospital were 2131, Population correction formula was used. By considering 10\% non-response rate, the final sample size was 357 . 
A list of all women of reproductive age (18-49 years), and 18 years and above for men who are living with HIV were selected and entered into computer SPSS window 16.0 version from HIMS data base. Computer generated simple random sampling technique was employed to select study respondents by using their Pre-ART card number. During the one -month study period, 340 PLHIVs were recruited into the study by randomly selection.

For qualitative study; all mother support group (four from four mothers) and all peer educators (six from six peer educators) were recruited purposively based on their duration of follow up greater than 10 years and they are expert patient of PLHIV who are working in the hospital.

\section{Data collection procedures}

Data were collected by face to face interview by using structured, pre-tested Amharic and Afan Oromo version questionnaire. The questionnaires were initially prepared in English and translated to Afan Oromo and Amharic and back to English by language experts and researchers to keep the consistency of the questionnaires. Two welltrained diploma nurses who are working in the ART clinic had collected data and one BSC Nurse had supervised during data collection period. Data collectors had cross checked Pre-ART card numbers of all clients who came to ART clinic with sampled card numbers daily.

The filled questionnaires were checked for consistencies and completeness daily by supervisor and principal investigators on the spot. Pre-test of the questionnaire were done on $5 \%$ of the sample of PLHIV in Kuyu Hospital which is nearby to Fitche town, to identify any ambiguity, consistency and acceptability of questionnaire, and then necessary corrections were made before the actual data collection.

Qualitative data was collected by ART focal person through in-depth interview by using semi-structured interview guide and conducted in separate room. Voice recorder and field-notes were used to capture the information obtained from the in-depth interview.

\section{Data processing and analysis}

After data collection, each questionnaire was checked for completeness and code was given before data entry. Data was entered, sorted, edited and cleaned for missed values. Data were analyzed by using SPSS version 16.0 statistical packages and presented by frequencies and percentages for categorical variables and means and standard deviations for numerical variables. Bivariate analysis was conducted primarily to check the variables which had an association with the dependent variable individually. Variables associated with the dependent variables at $p$ value $<0.2$ were then entered in to multiple logistic regression for controlling the possible effect of confounders and finally the variables which had significant association with fertility desire were identified on the basis of adjusted odds ratios (AOR), with 95\% CI and p-value $(<0.05)$ to fit into the final regression model. The results were presented using tables, figures and narratives.

\section{Qualitative data}

To add an in-depth of information on fertility desires that could not be captured by quantitative methods alone. Data captured using tape records was translated word by word into English language and color coded, organized and summarized manually under the main thematic area and presented the result by extracted concepts from main themes.

\section{Operational definition \\ Fertility desires}

A psychological state in which someone has the personal motivation to have a child. Those who have motivation to have more children in the future have fertility desire (have fertility desire). Those who have no motivation to have more children have no fertility desire (have no fertility desire).

\section{Ethical consideration}

Ethical clearance letter was initially obtained from Jimma University College of Public Health and Medical Sciences Ethical Committee. Then written consent was secured from Fitche hospital and permission was secured. Verbal informed consent for participation and audio recording of the discussions was obtained from each participant and the collected data were stored in a file, without the name of study participant and password protection of soft copy data and use of key and lock for hard copy data was employed to guarantee confidentiality.

\section{Result}

\section{Socio demographic characteristics}

Of 357 sampled PLHIVs, data were collected from 340 which give a response rate of $95.2 \%$. Among study participants majority 214(62.9\%) were females, $144(42.4 \%)$ were between the age 30-39 years and range from 18-70 years for males and 18-49 years for females with a mean age of $36.2 \pm 9.2$ years. Concerning ethnicity, majority of the respondents $265(77.9 \%)$ were Oromo and $325(95.6 \%)$ of the respondents were Orthodox in religion. With regard to educational status, 132(38.8\%) were illiterate and 184(54.1\%) were attended primary to secondary school. Concerning occupational status 78(22.9\%) were daily labour and family monthly income distribution of respondents, 94(27.6\%) had an income less than equal to $\leq 350$ birr per month with average monthly income was $735.9 \pm$ 631.48 standard deviation Ethiopian birr (1USD $=18.42$ Birr) (Table 1). 
Table 1 Sociodemographic characteristics of 340 PLWHA attending ART clinic in Fitche Hospital, Ethiopia, 2013G.C

\begin{tabular}{|c|c|c|c|}
\hline $\begin{array}{l}\text { Socio-demographic } \\
\text { variables }\end{array}$ & Categories & $\begin{array}{l}\text { Frequency } \\
\text { (n) }\end{array}$ & $\begin{array}{l}\text { Percent } \\
\text { (\%) }\end{array}$ \\
\hline \multirow[t]{2}{*}{$\operatorname{Sex}(n=340)$} & Male & 126 & 37.1 \\
\hline & Female & 214 & 62.9 \\
\hline \multirow[t]{3}{*}{ Age $(n=340)$} & $18-29$ years & 85 & 25.0 \\
\hline & 30-39years & 144 & 42.4 \\
\hline & $>40+$ years & 111 & 32.6 \\
\hline \multirow[t]{3}{*}{ Ethnicity $(n=340)$} & Oromo & 265 & 77.9 \\
\hline & Amhara & 73 & 21.5 \\
\hline & Others & 2 & 0.6 \\
\hline \multirow[t]{3}{*}{ Religion ( $n=340$ ) } & Orthodox & 325 & 95.6 \\
\hline & Protestant & 13 & 3.8 \\
\hline & Muslim & 2 & 0.6 \\
\hline \multirow[t]{6}{*}{ Occupation ( $n=340$ ) } & Daily labor & 78 & 22.9 \\
\hline & Merchant & 77 & 22.6 \\
\hline & Gov't employed & 43 & 12.6 \\
\hline & House wife & 65 & 19.1 \\
\hline & Farmer & 57 & 16.8 \\
\hline & Unemployment & 20 & 5.9 \\
\hline \multirow{4}{*}{$\begin{array}{l}\text { Level of school } \\
(n=340)\end{array}$} & Illiterate & 132 & 38.8 \\
\hline & $\begin{array}{l}\text { Primary and secondary } \\
(1-8)\end{array}$ & 118 & 34.7 \\
\hline & $\begin{array}{l}\text { High school and } \\
\text { preparatory school(9-12) }\end{array}$ & 66 & 19.4 \\
\hline & College and above & 24 & 7.1 \\
\hline \multirow{4}{*}{$\begin{array}{l}\text { Marital status } \\
(n=340)\end{array}$} & Married & 195 & 79.1 \\
\hline & Single & 19 & 8.8 \\
\hline & Windowed & 56 & 12.1 \\
\hline & Divorced/separated & 70 & 20.5 \\
\hline \multirow{4}{*}{$\begin{array}{l}\text { Family Income } \\
(\mathrm{n}=340)\end{array}$} & $<=350$ birr & 94 & 27.6 \\
\hline & 351-500 birr & 81 & 23.8 \\
\hline & 501-999 birr & 105 & 30.9 \\
\hline & $>=1000$ birr & 60 & 17.6 \\
\hline \multirow[t]{2}{*}{ Residence $(n=340)$} & Urban area & 271 & 79.7 \\
\hline & Rural area & 69 & 20.3 \\
\hline
\end{tabular}

Key: others (Tigrie \& Agnuwak).

\section{Sexual activity and contraceptive use information of PLHIV}

The majority of respondents 234(68.8\%) were sexually active. Of which $203(86.76 \%$ ) had sex with regular partner (husband/wife) and 31(13.24\%) were had multiple sexual partners. From the total study participants about $87(25.6 \%)$ of them were changed their sexual partner since HIV diagnosis.

The majority of them $169(60.8 \%)$ were used condom, of which $120(71.0 \%)$ used always. Eighty one $(48.0 \%)$ of them used dual methods of contraceptive by themselves or their partners of which majority, 73(90.1\%) were used
Depo-Provera in addition to condom. The main reason mentioned for use of condom, 115(33.8\%) were reported that for dual protection (pregnancy/STI/HIV), 35(10.3\%) to protect a negative partner, $15(4.4 \%)$ fear of re-infection with new stain of HIV and 4(1.2\%) advised by health professionals. Whereas for those not used condom the main reasons mentioned were partner objection, feeling it was not comfortable and desired to conceived which account 59(17.4\%), 25(7.4\%) \& 24(7.1\%) respectively.

Table 2 shows that the majority 290(85.3\%) had living children. From them $59.4 \%$ had 1 - 3children and $25.9 \%$ had more than 4 children whereas only $50(14.7 \%)$ had no biological living children. From those who had biological children $24(8.3 \%)$ were previously died related to HIV/AIDs and/or other diseases after learnt their or their partners' serostatus.

From the total interviewed PLHIV' about 83(24.4\%) had at least one pregnancy by themselves or their partners post-HIV diagnosis of which $62.7 \%$ was planned. The outcomes of these pregnancies were $66.3 \%$ live birth, $14.5 \%$ abortion, $7.25 \%$ still birth and $12.0 \%$ currently pregnant (during study period). The majority of in-depth interview discussants supported this finding, for instance: - as one 24 years female discussant stated: "I want to give birth because my husband is need child to replace ourselves. So, I have to get pregnant soon while my health is good enough. We gotten PMTCT and ART help from hospital, so I don't have any fear my child will be free of HIV and currently pregnant".

Table 2 shows that more than half 104(51.2\%) partners had fertility desire. Of total respondents about 99(29.1\%) was faced their family's pressure and $80(23.7 \%)$ had community pressure for having children. This finding is supported by majority of in-depth interview discussants, for example: - as one 45 yrs/Male explained: "Bearing children is important as one with no children is forgotten when died. Wealth shall be transferred to children otherwise it is lost. My parents and community will not respect me and my property. One without child is not considered born and the community called them as 'mule/infertile endwodi'.

\section{Fertility desire of PLHIV}

Out of 340 PLHIV interviewed 133(39.1\%) with 95\% CI of $(34.3 \%-44.3 \%)$ had fertility desire of which $24(18.0 \%)$, $18(13.5 \%), 33(24.8 \%)$ and $58(43.6 \%)$ were desired to have child within next 12 months, within one to 3 years, after three years and did not decided the time when to have children respectively. The main reasons mentioned for their current fertility desire were $36.8 \%$ wanted to replaced themselves, $38.3 \%$ did not have desired number of children and $20.3 \%$ believed that by using ART/ PMTCT to get HIV free baby (perceived efficacy of PMTCT and ART) and others reasons like to strength 
Table 2 Reproductive history and Fertility desire of PLHIV attending ART clinic in Ethiopia 2013

\begin{tabular}{|c|c|c|}
\hline Variables & $\begin{array}{l}\text { Frequency } \\
\text { (n) }\end{array}$ & $\begin{array}{l}\text { Percent } \\
(\%)\end{array}$ \\
\hline Number of living children & $n=340)$ & \\
\hline No living child & 50 & 14.7 \\
\hline 1 to 3 children & 202 & 59.4 \\
\hline$\geq 4$ children & 88 & 25.9 \\
\hline Child died related HIV before & $n=290$ & \\
\hline Yes & 24 & 8.3 \\
\hline No & 266 & 91.7 \\
\hline Pregnant or partner pregnancy since HIV-Dx & $n=340$ & \\
\hline Yes & 83 & 24.4 \\
\hline No & 257 & 75.6 \\
\hline Did you have fertility desire & $N=340$ & \\
\hline Yes & 133 & 39.1 \\
\hline No & 207 & 60.9 \\
\hline When do you desire to have a child? & $n=133$ & \\
\hline Within next 12 months & 24 & 18.0 \\
\hline Within one to three years & 18 & 13.5 \\
\hline After three years & 33 & 24.8 \\
\hline Not decided when to have a child & 58 & 43.6 \\
\hline $\begin{array}{l}\text { Take action to become pregnant/your } \\
\text { partner's? }\end{array}$ & $n=340$ & \\
\hline Yes & 35 & $10.3 \%$ \\
\hline No & 305 & $89.7 \%$ \\
\hline What kinds of action did you take? & 35 & \\
\hline stop take contraceptive methods & 17 & $48.6 \%$ \\
\hline discussed fertility intentions with caregivers & 11 & $31.4 \%)$ \\
\hline approach to their partner & 7 & $20.0 \%$ \\
\hline $\begin{array}{l}\text { Number of children desire to have in the } \\
\text { future? }\end{array}$ & $n=133$ & \\
\hline One child & 77 & 57.9 \\
\hline$\geq 2$ children & 56 & 42.1 \\
\hline Reason for their current fertility desire & $n=133$ & \\
\hline Want at least one child & 49 & 36.8 \\
\hline I did not have desired number & 51 & 38.3 \\
\hline To strengthen marriage & 4 & 3.0 \\
\hline Perceived efficacy of ART/PMTCT & 27 & 20.3 \\
\hline To replace died baby before & 2 & 1.5 \\
\hline Preference of sex for future fertility desire? & $n=133$ & \\
\hline Male & 41 & 30.8 \\
\hline Female & 23 & 17.3 \\
\hline No preference(God knows) & 69 & 51.9 \\
\hline Desire of a partner to have child? & $n=203$ & \\
\hline Yes & 104 & 51.2 \\
\hline No & 99 & 48.8 \\
\hline
\end{tabular}

Table 2 Reproductive history and Fertility desire of PLHIV attending ART clinic in Ethiopia 2013 (Continued)

\begin{tabular}{|c|c|c|}
\hline $\begin{array}{l}\text { Disscuss fertility intention with health } \\
\text { profession }\end{array}$ & $n=340$ & \\
\hline Yes & 137 & 40.3 \\
\hline No & 203 & 59.7 \\
\hline $\begin{array}{l}\text { Did you face partners or your family pressure } \\
\text { for child birth? }\end{array}$ & $n=340$ & \\
\hline Yes & 99 & 29.1 \\
\hline No & 241 & 70.9 \\
\hline $\begin{array}{l}\text { Did you faced community pressure for child } \\
\text { birth? }\end{array}$ & $n=340$ & \\
\hline Yes & 82 & 24.1 \\
\hline No & 258 & 74.9 \\
\hline
\end{tabular}

their marriage and replacing previously died baby. Of the total respondents $35(10.3 \%)$ were taken action to been pregnant or their partners. Of which $17(48.6 \%)$ were stopped taken contraceptive methods.

From those who have fertility desire about $77(57.9 \%)$ and 56(42.1\%) will have future desire number of a child, one and more than two children in the future and ranges from 1 to 4 children to achieved their fertility desire respectively. A 30 years woman described: "I have a boy and a girl so I need a brother for son and a sister for my daughter when my health is improved and CD4 is better and after I discussed with health professions. My husband has no biological child before he want child strongly, in the presence of treatment having children is preferable as it is to replace one self and it is natural to do so", With regarding to the preference of sex of child born in the future about $69(51.9 \%)$ were not preferred any sex and 41(30.8\%) was preferred male sex.

The main reasons mentioned for their current fertility desire were $36.8 \%$ wanted at least one child to replaced themselves, $38.3 \%$ did not have desired number of children and $20.3 \%$ believed that by using ART/PMTCT to get HIV free baby (perceived efficacy of PMTCT and ART) and others reasons like to strength their marriage and replacing previously died baby. Of the total respondents $35(10.3 \%)$ were taken action to been pregnant or their partners of which $17(48.6 \%)$ were stopped taken contraceptive methods. Out of the total study participants only $137(40.3 \%)$ were discussed about fertility intentions and others reproductive health needs with health professionals during follow up care.

With regarding to PLHIV who have no fertility desire $207(60.9 \%)$ were mentioned their main reasons for not having fertility desire; 69(33.3\%), 59(28.5\%), 34(16.4\%) and $45(21.7 \%)$ were lack of adequate income, already achieved desired numbers of children, child bearing compromised their or partner's health and the rest mentioned fear of MTCT and fear of infected their partner 
while try to conceive respectively. This finding is supported by most of in-depth interview discussants, for instance: - as one 36 years Woman discussant explained: "I have three children, me and the smallest are on ART but my husband is negative. Now I feel very sorry for the suffering of my baby hence I do not repeat the same sin by bearing positive child."

Table 3 showed that Out of the total study participants 209(61.5\%) had good knowledge about prevention of mother-to-child transmission of HIV (PMTCT), of which 136(63.6\%) were women and 73(57.9\%) were men. On the other hand, with regarding to HIV transmission from mother to child about 298(87.6\%) study respondents were knowledgeable and 202(59.4\%) have positive attitude towards PMTCT.

\section{Factors associated with fertility desire among PLHIV}

(Table 4 below) factors found significantly predictive of fertility desire for PLHIV to have more children were: Age from 18-29 years were 3.95 times [AOR, (95\% CI), $3.95(1.69-9.22)$ and $30-39$ years were 3.91 times (1.90 8.20)] more likely to have fertility desire as compared to age $40+$ years respectively.

PLHIVs marital length less than 4 years 5.5 times [AOR, (95\% CI), 5.5(2.08-14.51), from 5-9 years 4.8 times (2.14-10.78) and 10-14 years were 2.8 time (1.20 6.63)] more likely to have fertility desire as compared to had more than 15 years marital length. The majority of in-depth interview discussants supported this finding, for instance: as one 30 years female discussant stated: "I want to give birth because my husband strongly desire to have children to replace ourselves, so I have to get pregnant after one year. I stayed with my husband for 6 six years without having a child and marriage without children is meaningless and does not long last. PLHIVs who had no biological living child was 11.4 times [AOR, (95\% CI), $11.42(3.27-39.90)$ and 1 to 3 children were 3.67 times (1.27- 10.62)] more likely to have fertility desire as compared to had more than 4 biological living children. PLHIVs who faced community pressure for child birth was 3.67 times [AOR, (95\% CI), $3.67(1.54-8.70)]$ more likely to have fertility desire as compared to not faced community pressure for child birth. Those who have partner's had fertility desire was 7.18 times [AOR, (95\% CI), 7.18(3.39- 15.22)] more likely to have fertility desire as compared to those who have no fertility desire partner.

Among HIV related treatments and social support variables those enrolled for ART less than or equal to $\leq 1$ years was 5 times [AOR, (95\% CI), 5.0(1.91- 13.09)] more likely to have fertility desire as compared to more than 5 year since enrolled to ART and also the majority of in-depth interviews discussants supported this, for example:-as one 40 years Male discussant explained:" I need a child strongly.
It gives me self-esteem and value so, no loneliness. I proved PLHIVs can get negative child that is why I desire strongly after five years. I have a three and half year old negative child which I got after started ART and happy now".

PLHIV disclosed HIV-serostatus to their partner was 3.9 times [AOR, (95\% CI), 3.9(1.37- 11.10)] more likely to have fertility desire as compared to those not disclosed their serostatus to their partner. PLHIVs partner discordant was 2 times [AOR, (95\% CI), 2.05(1.01- 4.15)] more likely have fertility desire as compared to those concordant HIV-serostatus partner (Table 4).

\section{Discussions}

The prevalence of fertility desire of PLHIV in this study was $39.1 \%$, which is lower than EDHS 2011, study conducted in Cape Town South Africa and Nigeria, which account $63 \%, 51 \%$ and $63.3 \%$ respectively $[3,13,17]$. This may be due to different sociodemographic characteristics of the populations and cultural difference towards having large family size and fertility rate.

In this study PLHIV who mentioned their main reasons for current fertility desire were wanted at least one child to replaced themselves, did not have desired number of children and believed that by using ART/PMTCT to get HIV free baby (perceived efficacy of PMTCT and ART) and others reasons like to strength their marriage and replacing previously died baby. This is similar with study done in Rural Malawi rural, Uganda, New Guinea, Ethiopia (Addis Ababa and Nekemte) in which their main reasons were: wanting at least one child/more children, to reach ideal family size, no live child, wanting a different sex, support in old age, family/partners influence to have children, marriage, replacing previous died child and sufficient financial means as important in their fertility desires for PLHIV [15,16,18-20]. These indicate that the need for reproductive health services of PLHIVs in HIV care settings were need more comprehensive care in order to meet the PLHIV's diverse reproductive intentions for those who are intended to have children.

Multivariable logistic regression indicates that age was significant predictors of fertility desire with age within 18-29 and 30-39 years were 4 and 3.9 times more likely have fertility desire as compared to age 40 years respectively. This is similar with studies in Brazil, United States, South Africa, Uganda and Nigeria [12,21-24] have showed that younger PLHIV are more likely to desire (more) children than older PLHIV. The possible explanation may be due to that relatively older PLHIV have already achieved, or are closer to achieving, their desired family size than younger PLHIV. This has public health importance as many new HIV infections are occurring in younger PLHIV.

The number of surviving children was predictor of fertility desires PLHIV who have no biological living 
Table 3 Disease related factors of PLHIV attending ART clinic in Fitche Hospital Ethiopia, 2013

\begin{tabular}{|c|c|c|}
\hline Variables & $\begin{array}{l}\text { Frequency } \\
\text { (n) }\end{array}$ & $\begin{array}{l}\text { Percent } \\
\text { (\%) }\end{array}$ \\
\hline HIV transmits from mother to child? & $n=340$ & \\
\hline Yes & 298 & 87.6 \\
\hline No & 42 & 12.4 \\
\hline Time of MTCT? & $n=340$ & \\
\hline During pregnancy & 224 & 65.9 \\
\hline During labor & 163 & 47.9 \\
\hline During breast feeding & 140 & 41.2 \\
\hline Have information about PMTCT & $n=340$ & \\
\hline Yes & 216 & 63.5 \\
\hline No & 124 & 36.5 \\
\hline Attitude toward PMTCT? & $n=340$ & \\
\hline Yes (positive attitude) & 202 & 59.4 \\
\hline No (negative attitude) & 138 & 40.6 \\
\hline Knowledge about PMTCT? & $n=340$ & \\
\hline Knowledgeable & 209 & 61.5 \\
\hline Not knowledgeable & 131 & 38.5 \\
\hline Start ART & $n=340$ & \\
\hline Yes & 310 & 91.2 \\
\hline No & 30 & 8.8 \\
\hline Partner HIV status? & $n=203$ & \\
\hline Positive (concordant) & 143 & 70.4 \\
\hline Negative (discordant) & 60 & 29.6 \\
\hline Your partner started ART if HIV + Ve? & $n=143$ & \\
\hline Yes & 100 & 70.0 \\
\hline No & 43 & 30.0 \\
\hline Duration of time since enrolled to ART? & $n=340$ & \\
\hline 6 months to 1 year & 50 & 14.7 \\
\hline 2 to 4 years & 130 & 38.2 \\
\hline$\geq 5$ years & 160 & 47.1 \\
\hline Current CD4 count? & $n=340$ & \\
\hline$\leq 350$ cells $/ \mathrm{m} 3$ & 153 & 45.0 \\
\hline$\leq 350$ cells $/ \mathrm{m} 3$ & 187 & 55.0 \\
\hline WHO stage when enrolled to ART? & $n=340$ & \\
\hline Stage 1 & 59 & 17.4 \\
\hline Stage 2 & 48 & 14.1 \\
\hline Stage 3 & 222 & 65.3 \\
\hline Stage 4 & 11 & 3.2 \\
\hline Disclosed HIV status to partner? & $n=223$ & \\
\hline Yes & 195 & 87.4 \\
\hline No & 28 & 12.6 \\
\hline Disclosed HIV serostatus to family? & $n=340$ & \\
\hline Yes & 254 & 74.7 \\
\hline No & 86 & 25.3 \\
\hline
\end{tabular}

Table 3 Disease related factors of PLHIV attending ART clinic in Fitche Hospital Ethiopia, 2013 (Continued)

\begin{tabular}{lll}
\hline Difference in fertility desire after started HAART? & $n=310$ & \\
Yes & 103 & 33.2 \\
No & 207 & 66.8 \\
$\begin{array}{l}\text { Current health status affected future child } \\
\text { bearing intention? }\end{array}$ & $n=340$ & \\
Yes & 204 & \\
No & 136 & 60.0 \\
\hline
\end{tabular}

children and those who have few or 1 to 3 children were 11.4 times and 3.6 times more chance to have fertility desire as compared to those who have more than 4 biological living children. This finding is in line with other studies done in the United States, Brazil; Nigeria and Malawi and in Ethiopia studies in Addis Ababa and Nekemte town $[15,16,20,21,24,25]$ and South Africa [13,22], Uganda $[18,23]$. PLHIV, like anyone else, continue to desire (more) children until they achieve their desired family size.

PWLHAs marital length less than 4 years, within 5-9 years and 10-14 years were 5.5, 4.8 and 2.8 times were more likely have to fertility desire as compared to those marital lengths more than 15 years. This may be due to relatively PLHIV who have longer marital duration have already achieved, or are closer to achieving, their desired family size than shorter marital length PLHIVs'.

PLHIV' faced community pressure for having children was 3.7 times more likely have fertility desire as compared to those not faced community pressure for having children. This finding is consistent with studies in many societies and especially in SSA with those who are childless receiving negative social disapproval. The value of children in the identity and social status of men and women applies to PLHIV as well, and so they are under intense pressure from family, spouses and friends to reproduce $[5,26,27]$. This may be due to having children may re-establish the PLHIV with higher self-esteem, may help them restore a sense of normalcy in family life and health, and alleviate (mitigate) the potentially dehumanizing effects of living with HIV. Partner fertility desire was 7 times more likely have fertility desire as compared to those who have no partner. This is in line with the study done in South Africa and Ethiopia in Addis Ababa, South Wollo and Nekemte town $[16,20,22,28]$. This suggests that family planning and fertility related issues information should focus on partner as well.

PLHIV duration since HIV-diagnosis less than or equal to $\leq 1$ years was 5 more likely to have fertility desire as compared to those who more than 5 year. One explanation would be that the PLHIV enrolled to ART for a longer period might have gone through extensive health education that might have influenced their intentions unlike those that have just enrolled to ART. The 
Table 4 The overall fertility desire predictors of PLHIV attending ART clinic in Fitche Hospital, Ethiopia, 2013G.c

\begin{tabular}{|c|c|c|c|c|}
\hline \multirow[t]{2}{*}{ Variables } & \multicolumn{2}{|c|}{ Fertility desire $(n=340)$} & \multirow[t]{2}{*}{ COR $(95 \% \mathrm{Cl})$} & \multirow[t]{2}{*}{ AOR $(95 \% \mathrm{Cl})$} \\
\hline & Yes (\%) & No (\%) & & \\
\hline \multicolumn{5}{|l|}{ Age } \\
\hline $18-29$ years & $46(13.5)$ & $39(11.5)$ & $4.51(2.41,8.45)^{* * *}$ & $3.95(1.69,9.22)^{* * *}$ \\
\hline $30-39$ years & $64(18.8)$ & $80(23.5)$ & $3.06(1.74,5.38)^{* * *}$ & $3.91(1.90,8.20)^{* * *}$ \\
\hline$>=40$ years & $23(6.8)$ & $88(25.9)$ & 1.00 & 1.00 \\
\hline \multicolumn{5}{|c|}{ Duration stayed with partner/marital length $(n=203)$} \\
\hline$\leq 4$ years & $24(11.8)$ & $13(6.4)$ & $5.333(2.25,12.63)^{* * *}$ & $5.49(2.08,14.51)^{* * *}$ \\
\hline $5-9$ years & $34(16.7)$ & $20(9.9)$ & $2.63(1.170,5.89)^{* * *}$ & $4.80(2.14,10.78)^{* * *}$ \\
\hline $10-14$ years & $20(9.9)$ & $22(10.8)$ & $2.031(2.275,10.60)^{* *}$ & $2.82(1.19,6.63)^{* *}$ \\
\hline$>15$ years & $18(8.9)$ & $52(25.6)$ & 1.00 & 1.00 \\
\hline \multicolumn{5}{|c|}{ Number of living children } \\
\hline have no living child & $38(11.2)$ & $12(3.5)$ & $20.06(8.24,48.83)^{* * *}$ & $11.42(3.27,39.90)^{* * *}$ \\
\hline have 1 to 3 children & $83(24.4)$ & $119(35)$ & $4.540(2.24,9.21)^{* * *}$ & $3.67(1.27,10.615)^{* *}$ \\
\hline have $\geq 4$ children & $12(3.5)$ & $76(22.4)$ & 1.00 & 1.00 \\
\hline \multicolumn{5}{|c|}{ Face community pressure for having children } \\
\hline Yes & $61(18.0)$ & $19(5.6)$ & $8.29(4.63,14.85)^{* * *}$ & $3.67(1.54,8.704)^{* * *}$ \\
\hline No & $72(21.3)$ & $186(55.0)$ & 1.00 & 1.00 \\
\hline \multicolumn{5}{|l|}{ Partner fertility desire } \\
\hline Yes & $78(22.9)$ & $26(7.6)$ & $13.04(6.74,25.25)^{* * *}$ & $7.18(3.39,15.22)^{* * *}$ \\
\hline No & $20(5.9)$ & $79(23.2)$ & 1.00 & 1.00 \\
\hline \multicolumn{5}{|l|}{ Duration since HIV Dx } \\
\hline 6 months to 1 year & $27(7.9)$ & $23(6.8)$ & $2.24(1.176,4.27)^{* *}$ & $5.0(1.91,13.09)^{* * *}$ \\
\hline 2 to 4 years & $51(15.0)$ & $79(23.2)$ & $1.82(0.942,3.51)^{*}$ & \\
\hline$\geq 5$ years & $55(16.2)$ & $105(30.9)$ & 1.00 & 1.00 \\
\hline \multicolumn{5}{|c|}{ Disclose HIV status to partner $n=223$} \\
\hline Yes & $90(40.4)$ & $105(47.1)$ & $3.14(1.22,8.09)^{* *}$ & $4.09(1.26,13.30)^{* *}$ \\
\hline No & $6(2.7)$ & $22(9.9)$ & 1.00 & 1.00 \\
\hline \multicolumn{5}{|c|}{ Partner HIV status ( $n=203$ ) } \\
\hline Positive (concordant) & $74(36.5)$ & $69(34.0)$ & 1.00 & 1.00 \\
\hline Negative (discordant) & $20(9.9)$ & $40(19.7)$ & $2.15(1.14,4.02)^{* *}$ & $2.05(1.012,4.15)^{* *}$ \\
\hline
\end{tabular}

Note: ${ }^{* * *} p<0.001, * * p<0.05$.

influence of longer time since diagnosis of infection probably reflects the cumulative effects of decisions made by individuals who had weighed the consequences of their wish for parenthood over several months or years. Health professionals at different levels of institution should to be discontinuing from the conventional systematic advice against pregnancy but, in addition to laying emphasis on the risks, provide adequate information on the efficacy of PMTCT and practicable reproductive options for HIV-positive individuals.

PLHIV disclosure HIV-serostatus to partner was 4 times more likely have fertility desire as compared to those who do not disclosed their serostatus to their partner. This may be due to those who had disclosed their status have more discussion on their desired number of children than others and also PLHIV may want to have children to avoid stigma and secrete their status; to ensure family continuity in the future, to have offspring of their own to perpetuate their name and lineage after they die, and to be supported in old age.

PLHIV partners serodifference or discordant was 2 times more likely to have fertility desire. This is in line with other studies conducted in Uganda and Burkina Faso $[23,29]$. This observation could be explained by the fact that, as this study shows it, some young people still ignore the modes of HIV infection. Moreover, the issue of conception would be particularly important as means to avoid partner infection should be vital that needs consideration on alternative options/technologies. Health professional's work in ART clinics should be given 
attention for those coming for VCT and Provider Initiated HIV test and counseling by providing health messages about fertility, vertical transmission of HIV for discordant couples in this context is vital to ensuring informed reproductive decisions among PLHIVs and also encourage on disclosure of HIV-serostatus to their partner. On this research by considering the main strength of this research lies in its computer generated random sampling strategy for data collection, and the fact that used qualitative method to supplement the result and also to explore factors that are not addressed by quantitative survey. A set of reliability and validation rules were applied and all associated factors were taken after indication of significance in the "goodness of fit" for the models. Even though this study also had a few limitations: This study was facility-based among PLHIVs' that results were not generalizable to the general population in the community and cause and effect relation was not assured because of cross-section study deign.

\section{Conclusion}

The prevalence of fertility desire of PLHIV in the study area was $39.1 \%$. In this study:- age, marital length, biological child, partner, community pressure, duration of HIV-diagnosis, discordant HIV-test and disclosure of HIV-serostatus to partner were demonstrated to have more fertility desire among PLHIV and these factors should be emphatically considered during PLHIV's reproductive health program development. Therefore, Policy makers and health planners in the developing countries of sub Sahara African would better to plan and adapted assisted reproductive option/technologies for discordant partner which contribute to decrease HIV- new infections to sexual partner and new born.

\footnotetext{
Abbreviations

AIDS: Acquired immunodeficiency syndrome; ART: Antiretroviral therapy; AOR: Adjusted odd ratio; COR: Crude odd ratio; HAART: Highly active antiretroviral therapy; EDHS: Ethiopian demographic and health survey; FHAPCO: Federal HIV/AIDS prevention and control office; FMOH: Federal Ministry of Health; HIV: Human immunodeficiency virus; JU: Jimma University; MTCT: Mother-to-child transmission; PMTCT: Prevention of mother to child transmission; PLHIV: People living with HIV; SPSS: Statistical Package for Social Sciences; SSA: Sub Saran African; UNAIDS: Joint United Nations Programme on HV/AIDS; USD: USA dollar; WHO: World Health Organization; Y: Years.
}

\section{Competing interests}

The authors declare that they have no competing interests.

\section{Authors' contributions}

DBD:- conceptualized the study, designed the study instrument and conducted the data analysis and wrote the first draft and final draft of the manuscript. All co-authors:- BT and TT approved the proposal with some revisions, participated in data analysis, revised subsequent drafts of the paper and involve in critical review of the manuscript. All authors read and approved the final manuscript.

\section{Acknowledgement}

The authors are grateful to colleagues of the Fitche hospital and HIV treatment center and to the supervisor and data collectors who committed themselves throughout the study period.

Our thanks also go to all authors those who have availed their published articles free of charge for my literature review and Jimma University for giving this golden opportunity to undertake this research. Finally, we would like to express our gratitude to all participants who volunteered participated in the study.

\section{Author details}

${ }^{1}$ Department of Nursing and Midwifery, College of Medicine and Health Science, Ambo University, Ambo, Ethiopia. ${ }^{2}$ Department of Nursing and Midwifery, College of Public Health and Medical Sciences, Jimma University, Jimma, Ethiopia.

Received: 30 November 2013 Accepted: 23 October 2014

Published online: 20 November 2014

\section{References}

1. Joint United Nations Programme on HIV/AIDS(UNAIDS, Together We Will End AIDS report @2012 http://www.unicef.org/aids/files/ aids_togetherwewillendaids_en.pdf.

2. Global HIV AND AIDS Response: WHO/UNAIDS/UNICEF November 2011. http:// www.unaids.org/sites/default/files/media_asset/20121120_UNAIDS_Global_ Report_2012_with_annexes_en_1.pdf.

3. Ethiopia Demographic and Health Survey 2011. Addis Ababa, Ethiopia, Maryland, USA: Central Statistical Agency and ICF International Calverton; 2012.

4. Kodzi I, David J, John C: Examining the predictive value of fertility preferences among Ghanaian women. Demogr Res 2010, 22(30):965-984.

5. Cooper D, Jane Harries LM, Orner P, Bracken H: "Life is still going on": Reproductive intentions among HIV-positive women and men in South Africa. Soc Sci Med 2007, 65(2):274-283.

6. Oosterhoff P, Anh NT, Hanh NT, Yen PN, Wright P, Hardon A: Holding the line: Family responses to pregnancy and the desire for a child in the context of HIV in Vietnam. Cult Health Sex 2008, 10(4):403-416.

7. Delvaux T, Nöstlinger C: Reproductive choice for women and Men living with HIV: contraception, abortion and fertility. Reproductive Health Matters 2007, 15(29, Supple 1):46-66.

8. Segurado AC, Paiva V: Rights of HIV positive people to sexual and reproductive health:parenthood. Reproductive Health Matters 2007, 15(29, Supplement 1):27-45.

9. Spaulding AB, Bain Brickley D, Caitlin Kennedy LA, Laura Packel JM, Gail Kennedy LC, Osborne K: Linking family planning with HIV/AIDS interventions: a systematic review of the evidence. AIDS 2009, 23:S79-S88.

10. Hosegood V: The demographic impact of HIV and AIDS across the family and household life-cycle: implications for efforts to strengthen families in sub-Saharan Africa. AIDS Care 2009, 21(sup1):13-21.

11. Betru Tekle, Director General: Federal HIV Prevention and Control Office Federal HIV/AIDS Prevention and Control Office and Federal Ministry of Health: Guidelines for Prevention of Mother-to-Child Transmission of HIV in Ethiopia. Addis Ababa: FHAPCO; 2007.

12. Nóbrega AA, Oliveira FAS, GalvÃ£o MTG, Mota RS, Regina M, Barbosa ID, Kendall C, Kerr-Pontes LR: Desire for a child among women living with HIV/AIDS in northeast brazil. AIDS Patient Care \& STDs 2007, 21(4):261-267.

13. Cooper D, Jennifer Moodley VZ, Linda-Gail Bekker IS, Myer L: Fertility intentions and reproductive health care needs of people living with HIV in cape town, south Africa: implications for integrating reproductive health and HIV care services. AIDS Behav 2009, 13(supplement 1):38-46.

14. Nattabi B, Jianghong Li ST, Orach C, Earnest J: Family planning among people living with HIV in post-conflict Northern Uganda: A mixed methods study. Confl Heal 2011, 5(1):18.

15. Yeatman S: The impact of HIV status and perceived status on fertility desires in rural Malawi. AIDS Behav 2009, 13:12-19.

16. Regassa T, Fantahun M: Fertility Desire and Reproductive Health Care Needs of Men and Women Living with HIV/AIDS in Nekemte, East Wollege, Ethiopia. Sci Technol Arts Res J 2012, 1(3):31-38. www.starjournal. org. ISSN: 2226-7522.

17. Smith DJ, Mbakwem BC: Antiretroviral therapy and reproductive life projects: Mitigating the stigma of AIDS in Nigeria. Soc Sci Med 2010, 71(2):345-352. 
18. Kipp W, Heys J, Jhangri GS, Alibhai A, Rubaale T: Impact of antiretroviral therapy on fertility desires among HIV-infected persons in rural Uganda. Reprod Health 2011, 8(27). http://www.reproductive-healthjournal.com/ content/8/1/27, doi: 10.1186/1742-4755-8-27.

19. Aska ML, Chompikul J: Determinants of fertility desires among HIV positive women living in the Western highlands province of Papua New Guinea BoonyongKeiwkarnka. World Journal of AIDS ASEAN Institute for Health Development Mahidol University, Thailand 2011, 1:198-207.

20. Tamene W, Fantahun M: Fertility desire and family-planning demand among HIV-positive women and men undergoing antiretroviral treatment in Addis Ababa, Ethiopia African Journal of AIDS Research 2007. Afr J Aids Res 2007, 6(3):223-227. Printed in South Africa.

21. Finocchario-Kessler S, Michael Sweat JD, Maria Trent DK, Keller J, Anderson J: Understanding high fertility desires and intentions among a sample of urban women living with HIV in the United States. AIDS Behav 2010, 14(5):1106-1114.

22. Kaida A, Laher F, Strathdee SA, Janssen PA, Money D, Hogg RS, Gray G Childbearing intentions of HIV-positive women of reproductive Age in Soweto, south africa: the influence of expanding access to HAART in an HIV hyperendemic setting. Am J Public Health 2011, 101(2):350-358.

23. Kakaire $\mathrm{O}$, Osinde M, Kaye D: Factors that predict fertility desires for people living with HIV infection at support and treatment centre in Kabale. Uganda. Reprod Health 2010, 7(1):27.

24. Iliyasu Z, Isa Abubakar MK, Musa Babashani FS, Aliyu MH: Correlates of fertility intentions among HIV/AIDS patients in northern Nigeria. Afr J Reprod Health 2009, 13(3):71-83.

25. Paiva V, Naila Santos IF-J, Elvira Filipe JRA, Segurado A: Desire to have children: gender and reproductive rights of Men and women living with HIV: a challenge to health care in brazil. AIDS Patient Care \& STDs 2007 , 21(4):268-277.

26. Agadjanian V: Fraught with ambivalence:reproductive intentions and contraceptive choices in a Sub-Saharan fertility transition. Popul Res Policy Rev 2005, 24(6):617-645.

27. Wagner G, Sebastian Linnemayr CK, Mugyenyi P: Factors associated with intention to conceive and its communication to providers: among HIV clients in Uganda. Matern Child Health J 2011:1-9. ISSN: 1573-6628; Print ISSN 1092-7875.

28. Getachew M, Alemseged F, Abera M, Deribew A: Factors affecting fertility decisions of married men and women living with HIV in South Wollo Zone. Northeast Ethiopia. Ethiop J Health 2010, 24(3):214-220.

29. Simpore J, Compaore E, Sawadogo J, Djigma F, Ouermi D, Martinetto M, Pietra V, Fabó F, ten Have HAMJ, García A: Human immunodeficiency virus prevention among HIV-serodiscordant couples in Burkina Faso: bioethical and cultural challenges. World J AIDS 2011, 1:185-191.

doi:10.1186/s12884-014-0382-2

Cite this article as: Demissie et al:: Fertility desire and associated factors among people living with HIV attending antiretroviral therapy clinic in Ethiopia. BMC Pregnancy and Childbirth 2014 14:382.

\section{Submit your next manuscript to BioMed Central and take full advantage of:}

- Convenient online submission

- Thorough peer review

- No space constraints or color figure charges

- Immediate publication on acceptance

- Inclusion in PubMed, CAS, Scopus and Google Scholar

- Research which is freely available for redistribution

Submit your manuscript at www.biomedcentral.com/submit
C Biomed Central 